\title{
TRAJETÓRIA ESPORTIVA E HABILIDADES PSICOLÓGICAS DE JOGADORES DE FUTEBOL DA SELEÇÃO BRASILEIRA
}

\author{
SPORTS TRAJECTORY AND PSYCHOLOGICAL SKILLS OF \\ BRAZILIAN NATIONAL TEAM SOCCER PLAYERS C
}

TRAYECTORIA DEPORTIVA Y HABILIDADES PSICOLÓGICAS DE JUGADORES DE FÚTBOL DE LA SELECCIÓN BRASILEÑA. Cृ

doi' https://doi.org/10.22456/1982-8918.113626

Juliane Jellmayer Fechio*<jfechio@gmail.com>

Maria Stella Peccin** <stella.peccin@unifesp.br>

Ricardo da Costa Padovani** <ricardo.padovani@unifesp.br>

\footnotetext{
*Santos Futebol Clube; Confederação Brasileira de Skate; Universidade Federal de São Paulo. São Paulo, SP, Brasil.

**Universidade Federal de São Paulo. São Paulo, SP, Brasil.
}

\begin{abstract}
Resumo: O objetivo deste estudo foi compreender a construção da trajetória de jogadores de futebol profissional da seleção brasileira. Foram entrevistados seis jogadores de futebol, do gênero masculino, que faziam parte da equipe principal de clubes que disputam a primeira divisão do Campeonato Brasileiro. Critério de inclusão: mínimo de dois anos como jogador profissional e pelo menos uma convocação pela seleção brasileira de futebol. Os atletas foram entrevistados individualmente. A partir da análise das entrevistas, constatou-se que o futebol se apresenta como tema central em suas vidas e que a família tem um papel importante no contexto do esporte. A importância das habilidades psicológicas é confirmada para aqueles que atingiram a elite do futebol profissional e a seleção brasileira. A compreensão da trajetória esportiva de atletas da elite constitui um tema de grande relevância para o avanço da ciência do esporte.
\end{abstract}

Palavras chave: Competência Profissional. Futebol. Atletas. Psicologia do Esporte.
Recebido em: 02 mai. 2021 Aprovado em: 31 out. 2021 Publicado em: 26 dez. 2021

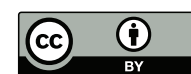

Este é um artigo publicado sob a licença Creative Commons Atribuição 4.0 Internacional (CC BY 4.0).

elSSN: 1982-8918 


\section{INTRODUÇÃO'}

O futebol constitui a modalidade esportiva mais popular do mundo e exerce importante expressão nas sociedades em diferentes partes do mundo. Sua expressão pode ser observada pela movimentação financeira, pela capacidade de reunir pessoas, gerar empregos, alimentar sonhos e proporcionar reações emocionais intensas e diversas de pessoas e grupos. Soma-se ainda o fato de o futebol se apresentar como importante meio de entretenimento para muitos grupos populacionais (PIMENTA, 2008; ANJOS; SANETO; OLIVEIRA, 2012; ROTTA, 2014; SANTOS et al., 2017; MATIAS, 2018).

Tornar-se um jogador de futebol profissional povoa o imaginário de uma parcela expressiva de jovens e familiares (WISNIK, 2008; ANJOS et al., 2012; BALZANO et al., 2019). No entanto, quando observam um atleta em atividade, não imaginam os anos de dedicação e disciplina necessários para o alcance do desempenho esportivo e, tampouco, que somente um número reduzido de atletas consegue chegar ao esporte de elite (KANNEKENS; ELFERINK-GEMSER; VISSCHER, 2011; WEINBERG; GOULD, 2017).

Atingir a excelência e manter-se em alto nível no esporte exige que o atleta se sobressaia nos domínios fisiológico, técnico, cognitivo (tático, estratégico, perceptual e tomada de decisão) e emocional (regulação emocional) (SARMENTO et al., 2018; DAVIDS; ARAÚJO, 2019; SCHARFEN; MEMMERT, 2019; KASUYA; NKAZAWA, 2019). Portanto, déficits nos domínios citados podem comprometer a aquisição e manutenção de níveis elevados de desempenho.

A literatura aponta a resiliência psicológica, a disciplina, a dedicação e a clareza na busca de seus objetivos como elementos importantes na melhoria e na manutenção do desempenho esportivo em níveis elevados (GALLI; GONZALEZ, 2014; WEINBERG; GOULD, 2017; VIDUAL; GOMES; FERNANDES, 2019). Somase a esse cenário o suporte da família e amigos, o papel exercido por treinadores e centros esportivos de formação (KASUYA; NKAZAWA, 2019; VIDUAL et al., 2019). O acesso a atletas de elite do futebol que representaram o país não é fácil para pesquisadores, o que prejudica o estudo científico da excelência esportiva da modalidade mais popular do Brasil.

Diante do exposto, o presente estudo buscou compreender a construção da trajetória esportiva e o emprego das habilidades psicológicas de jogadores de futebol de campo profissional que representaram a seleção brasileira.

\section{MÉTODO}

Trata-se de um estudo de natureza qualitativa, de amostragem intencional. O estudo foiaprovado pelo Comitê deÉtica em Pesquisa(CAAE:20795313.4.0000.5505). O período e o ano da coleta de dados foram omitidos para preservar o anonimato dos participantes.

1 Este artigo tem origem na tese do primeiro autor: Excelência no Esporte: uma análise das habilidades psicológicas e trajetória profissional de jogadores de futebol de campo de elite (tese de doutorado), Programa de Pós-graduação Interdisciplinar em Ciências da Saúde - Universidade Federal de São Paulo, 2017, 219 f. Disponível no repositório institucional e na Biblioteca da Universidade Federal de São Paulo. 


\subsection{PARTICIPANTES}

Participaram do estudo seis jogadores de futebol de campo, do gênero masculino, que faziam parte da equipe principal (profissional) de clubes que disputavam a primeira divisão do Campeonato Brasileiro. Foi adotado como critério de inclusão ter atuado como jogador profissional por pelo menos dois anos e ter sido convocado pela seleção brasileira de futebol de campo (na categoria profissional principal ou olímpica).

\subsection{INSTRUMENTO}

Roteiro de Entrevista Semiestruturado para Investigação da Trajetória de Jogadores de Elite de Futebol. Elaborado pelos autores a partir da literatura (FIGUEIREDO et al., 2009; WEINBERG; GOULD, 2017) e da experiência e contato da primeira autora com a área do futebol. O roteiro abordou os seguintes temas: escolaridade, estado civil, religiosidade, tempo no clube, histórico dos principais campeonatos e construção da trajetória profissional no futebol de campo.

\subsection{PROCEDIMENTO}

A primeira autora, a partir do contato profissional com jogadores de futebol de campo profissional, apresentou os objetivos e cuidados éticos envolvidos no estudo. Após a manifestação de interesse em participar do estudo, foi agendada a entrevista para realização da coleta de dados. A entrevista foi realizada individualmente em sala destinada ao atendimento de atletas, com duração média de 60 minutos. A assinatura do Termo de Consentimento Livre e Esclarecido (TCLE) formalizou a participação no estudo. Os participantes consentiram que a entrevista fosse gravada.

\subsection{ANÁLISE DOS DADOS}

As entrevistas foram gravadas em áudio e seu conteúdo transcrito ipsis litteris pela primeira autora. A análise dos dados considerou os seguintes procedimentos: leitura flutuante; leitura exaustiva; estabelecimento de unidades temáticas; unidade de contexto para definição das categorias temáticas e interpretações à luz da literatura, considerando o objetivo a ser respondido (MINAYO, 2014). As seguintes categorias temáticas emergiram: 1) realização do sonho de ser jogador de futebol; 2) Trajetórias: adversidades e resiliência; 3) Habilidades Psicológicas para o desenvolvimento da excelência esportiva; 4) Preparação psicológica para a competição; 5) Concentração: punição/privação.

\section{RESULTADOS E DISCUSSÃO}

A idade mínima foi de 23 anos e máxima de 38 anos. P1 tinha 27 anos; P2, 38 anos; P3, 25 anos; P4, 35 anos; P5, 23 anos e P6, 33 anos. Quatro participantes declararam que estavam casados, um noivo e um namorando. Apenas um participante não tinha filho. Três tinham o segundo grau completo, dois, o segundo incompleto e um, o primeiro grau completo. Cinco eram da religião católica e um da evangélica. A 
posição em que cada participante atuava foi omitida para evitar a sua identificação. O Quadro 1 apresenta os dados esportivos dos participantes.

Quadro 1 - Dados esportivos dos participantes.

\begin{tabular}{|l|c|c|c|c|c|c|}
\hline Dados Esportivos & P1 & P2 & P3 & P4 & P5 & P6 \\
\hline Início competições & 9 anos & 15 anos & 15 anos & 10 anos & 14 anos & 8 anos \\
\hline Tempo no profissional & 10 anos & 21 anos & 5 anos & 18 anos & 4 anos & 17 anos \\
\hline Convocações Profissional & 7 & 32 & 8 & 31 & 2 & 68 \\
\hline Elenco internacional & Não & Sim & Não & Sim & Sim & Sim \\
\hline
\end{tabular}

Fonte: dados da pesquisa

É possível notar que os participantes apresentam experiência no futebol profissional. Constata-se que metade dos participantes foi convocada para a seleção brasileira nas categorias de base e que dois jogadores não tinham atuado em times do exterior.

\subsection{SONHO DE SER JOGADOR DE FUTEBOL}

Ao serem convidados a falar sobre sua vida, o tema futebol ocupou a centralidade do discurso, sendo enfatizado o sonho de ser jogador de futebol. A família se revelou como elemento fundamental na concretização do sonho. Destacaram que esse sonho foi apoiado e incentivado pelos pais e que sua concretização proporcionou um futuro melhor para a família. Enfatizaram o futebol como trabalho e reconheceram as limitações que a profissão tem no convívio com a família.

O sonho de ser jogador de futebol se inicia antes de entrarem em campo, começa com a bola que a criança ganha, com o incentivo dos pais, a mídia exibindo o "glamour" da profissão e tantos outros cenários que remetem ao imaginário de ser jogador de futebol (PIMENTA, 2008; ROTTA, 2014). O futebol como um projeto de vida passa a ser idealizado como instrumento de realização pessoal e de participação social (PIMENTA, 2008) e o seu significado é reforçado pelos participantes da pesquisa quando questionados sobre a representação do futebol. O relato de P5 evidencia a importância do futebol na constituição de sua vida: "o futebol é 24 horas por dia, como que eu posso dizer... a gente tenta separar a vida do futebol, mas não dá, você acaba vivendo isso muito intensamente" (P5).

A representação do futebol pode ser observada no estudo de Bossle e Lima (2013), que, ao investigaram a percepção de atletas da categoria de base de dois clubes tradicionais de Porto Alegre sobre futebol e escola, verificaram que se trata de uma relação desigual na qual a formação no futebol tem prioridade em relação à formação na escola. A formação escolar se revela como um plano alternativo à não concretização do investimento no futebol ou como algo acessório a construção da carreira de jogador de futebol. A importância da escola foi reconhecida, mas não como prioritária naquele momento.

Verificou-sequeos atletasentrevistadossesentemrealizadosprofissionalmente. Ter alcançado o objetivo de ser jogador profissional, atuado em clubes de renomes 
e representado o país na seleção brasileira constituem marcadores importantes de suas realizações na carreira profissional. Nota-se que os atletas mais novos mantêm a meta de serem novamente convocados para a seleção principal. Os jogadores mais velhos, por sua vez, demonstram satisfação com a carreira profissional que construíram e apresentam metas vinculadas ao futebol, mesmo após o término da carreira. O relato abaixo ilustra essas observações:

\begin{abstract}
Queria disputar uma Copa do Mundo. Eu participei da Copa América, Copa das Confederações e na Copa de [ano omitido] eu acabei ficando fora [...] mas não fico com aquela obsessão: 'Ah eu tinha que disputar uma Copa do Mundo' era um sonho, não concretizou, passou, não disputei. Um sonho profissional que eu queria era uma Libertadores, que eu disputei, mas não ganhei, mas essa ainda dá [...] tive o sonho de jogar a Champions League e eu joguei, joguei na Europa, que eu queria também [...]. Mas o maior sonho que eu tive, que eu pedi nas passagens de ano eu consegui, que era ir para a seleção brasileira profissional, o resto era consequência. Eu fiz de tudo para chegar na seleção e consegui [...] creio que vou estar ligado ao futebol sempre, porque você que jogou futebol nunca mais consegue se distanciar dele. (P4, 35 anos).
\end{abstract}

O relato fortalece a afirmação de que o futebol se apresenta na vida dos entrevistados como tema central. Verbalizações como "o futebol é tudo para mim" e "o futebol é minha vida" surgiram com frequência nos discursos dos participantes. Nessa perspectiva, os achados de Brandão et al. (2008) sobre o significado do futebol na vida de jogadores de diferentes categorias reforçam a percepção positiva do futebol. Foram identificadas no estudo (BRANDÃO et al., 2008) categorias relacionadas à satisfação, meio de vida, competência, socialização e divertimento.

A atuação na seleção brasileira e em clubes renomados no cenário nacional e internacional constituem indicadores da concretização do sonho e o alcance da realização profissional. O lugar de destaque no futebol possibilita a alguns jogadores que sua imagem seja amplamente explorada pela mídia e ocupem o status de celebridade, reproduzindo a imagem de sucesso e de prestígio (PEREIRA, 2008; CAPRARO et al., 2011). Tais considerações evidenciam o processo de construção do imaginário "ser jogador de futebol" na sociedade.

\title{
3.2 TRAJETÓRIAS: ADVERSIDADES E RESILIÊNCIA
}

A trajetória esportiva dos participantes foi marcada pela superação de uma série de adversidades e obstáculos, como, por exemplo, mudança da cidade de origem e viver longe do convívio da família e de amigos, deixar vivências típicas da idade e conquistar reconhecimento pelo desempenho esportivo, habilidades psicológicas complexas exigidas precocemente. Os participantes do estudo alcançaram a equipe profissional antes de atingir a idade limite para disputar campeonatos nas categorias de base (20 anos) e, em função do desempenho, se destacaram precocemente.

As demandas e adversidades presentes ao longo das diferentes etapas da carreira esportiva podem ter importante impacto na permanência de atletas no esporte de alto rendimento (GONZÁLEZ; BORGES; SFALCIN, 2015; CARVALHO et al., 2017). Isso ficou evidente no discurso dos participantes do presente estudo, como no relato do P3: 
Comecei em time de bairro [...] e aí fui convidado para fazer o teste de um clube que por sinal era em frente à minha casa [...] fui comprado e aí muda tudo, né? Porque você está acostumado a viver com a sua família e eu tive que ir para muito longe, fiquei três anos lá e oscilei muito porque eu senti muita falta da minha família, dos meus amigos e cheguei ao ponto de pensar em parar, porque é uma carreira muito incerta. Nessa época eu fui até afastado pela direção, porque eu não estava conseguindo render o que eu podia. (P3, 25 anos).

O relato de P3 ilustra uma dificuldade comum a todos os participantes do estudo no início da trajetória esportiva, que foi viver longe da família ainda muito jovem. Nesse cenário, o suporte e o incentivo familiar para resistirem às adversidades e persistirem se revelaram centrais na permanência da carreira esportiva. Deve-se ponderar, nesse processo, a expectativa da família de que seu filho tenha uma carreira de sucesso no futebol e alcance a ascensão social (RIAL, 2006; ANJOS et al., 2012).

Rotta (2014) e Andrade (2016) destacam o papel desempenhado pela família na trajetória esportiva de filhos atletas. O relato de P4 (35 anos) ilustra a importância da família: [...] de lá pra cá, em todos os jogos que eu entro, eu sempre dedico para ela [mãe], tudo o que eu vou fazer dentro de campo, os gols, as vitórias, as conquistas que eu tive na vida sempre foram dedicadas a ela [mãe] e a minha família (P4, 35 anos).

A insegurança na carreira profissional de jogador de futebol é algo que aparece com frequência no discurso dos jogadores. Durante o processo de formação nas categorias de base, os atletas buscam concretizar seus sonhos, mas convivem diariamente com o medo da dispensa, da lesão e de terem dispensado um tempo precioso marcado por sacrifícios e, mesmo assim, não terem conseguido chegar ao futebol profissional. A resiliência psicológica tem sido um sido apontada como importante característica de atletas de elite (CRUST; AZADI, 2010; ROTTA, 2014; VIDUAL et al., 2019). O relato de P6 evidencia a importância da resiliência psicológica no processo de construção de sua carreira profissional:

\footnotetext{
Uma vez um treinador me mandou cortar cana. Eu estava sentado no chão e nós tínhamos perdido o jogo e ele me mandou cortar cana: 'Vai cortar cana com o seu pai em vez de ficar aqui me enchendo o saco'. Eu tinha só treze anos. Mas eu vi aquilo como um desafio: 'Não, esse cara está errado'. (P6, 33 anos).
}

Almeida Neto e Santos (2015) atentam para o fato de que, dentre os inúmeros aspectos que diferenciam o futuro jogador profissional, como, por exemplo, a habilidade técnica (saber jogar), a capacidade física (suportar o ritmo de treinos e jogos), a sua capacidade de resistir à pressão se apresenta como uma das principais características. Na linguagem dos jogadores, no futebol é preciso "matar um leão por dia". A perspectiva de resistir frente à adversidade se apresenta como um elemento comum para todos os participantes. A capacidade de resistir e a de responder positivamente às situações adversas constituem importantes características da resiliência (FLETCHER; SARKAR, 2012; MORGAN; FLETCHER; SARKAR, 2013; VIDUAL et al., 2019).

Quando questionados sobre os momentos mais difíceis na trajetória, foram apontados: problemas extracampo (separação dos pais, falecimento da mãe, 
falecimento do avô e adoecimento da mãe) (P1, P4); lesão (P3, P5); transição das categorias de base para o profissional (P6); aposentadoria (P2). O relato de P2 ilustra os desafios do processo da aposentadoria e a importância da Psicologia do Esporte nessa fase de sua carreira:

\begin{abstract}
A minha fase atual também está sendo muito difícil, que é a fase da aposentadoria. Nossa! Eu estou passando com psicólogo do esporte e estou conseguindo colocar para fora e eu sei o quanto está sendo benéfico, a gente tira um peso enorme das costas. [...] uma hora meu ciclo ia acabar e ele está acabando... é uma transição e essa transição não é uma coisa simples, fácil [...]. (P2, 38 anos).
\end{abstract}

Em relação às fontes de apoio nos momentos das adversidades, cinco participantes mencionaram a família. Nota-se que, mais uma vez, a família aparece como o principal suporte na trajetória dos jogadores. Inicialmente na figura dos pais e, posteriormente, na figura das esposas e filhos.

Estudos com atletas de elite têm apontado que mesmo em esportistas expoentes a necessidade de apoio familiar permanece. No entanto, o que muda é o tipo de suporte recebido, do financeiro, no início da carreira, para o emocional (CÔTÉ, 1999; MARQUES; SAMULSKI, 2009; FERREIRA; MORAES, 2012; REIS; FERREIRA; MORAES, 2016).

P2, por sua vez, cita o papel do psicólogo do esporte nos momentos de adversidade: "Para ser bem sincero? Contava comigo. Por isso que eu estou falando que hoje eu vejo que é fundamental, primordial, um psicólogo no esporte" (P2, 38 anos).

O relato do P2 ilustra a importância do psicólogo no esporte de alto desempenho. Aprender a gerenciar emoções e lidar com as demandas (pessoais e profissionais) impostas nos diferentes momentos da carreira, além da constante busca de níveis elevados de desempenho, constituem exemplos de habilidades importantes para o atleta de elite. Nessa perspectiva, o trabalho desenvolvido por um psicólogo do esporte terá um papel de fundamental importância. Trabalho que estará pautado não apenas na busca dos objetivos esportivos, mas também na qualidade de vida e saúde mental do atleta (RUEDA; LACERDA, 2017; WEINBERG; GOULD, 2017; BELL et al., 2020).

\title{
3.3 HABILIDADES PSICOLÓGICAS PARA O DESENVOLVIMENTO DA EXCELÊNCIA ESPORTIVA
}

A resistência mental tem sido considerada um atributo central para chegar ao esporte profissional e para atingir a excelência esportiva (COULTER; MALLETT; GUCCIARDI, 2010; RAMADAS; SERPA; ROSADO, 2012; WEINBERG; GOULD, 2017; VIDUAL et al., 2019). Dedicação, disciplina e determinação constituem exemplos de características mencionadas pelos participantes, corroborando a literatura (RAMADAS et al., 2012; ROTTA, 2014; COUTINHO; MESQUITA; FONSECA, 2016; WEINBERG; GOULD, 2017). Como exemplo de disciplina e dedicação, podem-se destacar os relatos de P2 e P3:

[...] não deixei os prazeres da vida tirarem meu foco. Porque você pode ter muitos amigos, companheiros de trabalho... ah! Vamos descansar, vamos sair, vamos ver um filme. [...] você precisa abdicar de alguma coisa para 
conseguir outra, nada vem sem esforço, nada cai do céu [...]. Foi a minha dedicação nos treinos e fora do campo que é tão ou mais importante. Porque fora do campo se você não se cuidar você não rende, não adianta, o corpo não é uma máquina. Se você não descansar, acabou. (P2, 38 anos).

[...] acho que a minha força de vontade foi suficiente para eu conseguir chegar onde eu estou hoje, vários momentos eu podia ter parado, ter largado o futebol e eu acho que muitos que jogam bem, que tem muita qualidade acabam se perdendo no meio do futebol por besteira, porque futebol tem muitas coisas erradas, balada, mulheres, que a gente tem que saber que o foco nosso é jogar futebol, meu foco sempre foi esse e acho que as pessoas se perderam por causa disso, tem muitos jogadores que podem falar que tem a mesma qualidade, só que, às vezes, não têm a mesma vontade. (P3, 25 anos).

A autodeterminação, o controle emocional na busca dos objetivos almejados e a crença na eficácia da realização pessoal são características encontradas entre atletas de elite (RAMADAS, SERPA; ROSADO, 2012; ROTTA, 2014; VIDUAL et al., 2019).

P6 ressaltou a importância das habilidades cognitivas, da motivação e dedicação para conquistar o futebol profissional.

\begin{abstract}
Eu acho que é muito mentalmente. Eu acho que o esporte ele é muito mental [...]. São certas decisões que você precisa tomar de posicionamento, de leitura de jogo [...]. Futebol é regra, situações acontecem e acontece a mesma coisa, várias vezes, ou de você ter que expor e falar alguma coisa ou de um treinador te colocar fora da posição e você ter que estar pronto para mesmo não querendo falar sim e você tem que se virar. Eu sempre fui esse cara. Eu fui para a seleção tinha três caras fenômenos na frente. Eu falei: 'Ah! Eu não vou jogar aqui, vou começar a jogar mais para trás, porque aí eu sei que vou jogar'. Criar esses hábitos, entendeu? E treinar, me dedicar, me concentrar em entender o que o treinador está falando, entender aquilo que o treinador queria. Você precisa ter uma sabedoria, não só dentro do campo. (P6, 33 anos).
\end{abstract}

O participante P6 menciona a leitura de jogo, tomada de decisão e obediência tática como um diferencial importante para chegar ao futebol profissional. A inteligência de jogo está relacionada a aspectos percepto-cognitivos que exercem importante papel no processo de antecipação e tomada de decisão em atletas de futebol de alto rendimento (CASANOVA et al., 2009; ROCA, 2011; ROCA; FORD; WILLIAMS, 2013; PETIOT et al., 2017).

Segundo Petiot et al. (2017), a literatura sugere que atletas de elite têm a capacidade de considerar as principais informações e gerar ações táticas adequadas. Conhecimento e memória de trabalho são determinantes para processar informações e tomar uma decisão tática de qualidade. Jogadores devem tomar decisões rápidas e precisas em um ambiente complexo e variável. As decisões dos atletas são feitas com base em informações que chegam de diferentes fontes, como a bola, os companheiros de equipe, os adversários. O processo de tomada de decisão ocorre sob pressão e com os oponentes tentando restringir o tempo e o espaço disponíveis (CASANOVA et al., 2009).

A busca constante pelo aperfeiçoamento das habilidades e a superação de adversidades se apresentam como características importantes para atletas de elite 
(THELWELL; GREENLEES; WESTON; 2010; FLETCHER; SARKAR,2012; SWANN; MORAN; PIGGOTT, 2015; LIEW et al., 2019). Os relatos de P1, P2 e P3 evidenciam esse processo de constante aprimoramento de suas capacidades.

Eu, quando faço uma partida muito boa, eu não me empolgo e quando eu faço uma partida ruim eu coloco na cabeça que na seguinte eu tenho que melhorar [...] eu me cobro bastante, eu me cobro estar jogando sempre em alto nível, sempre estar treinando bem, me chateia muito estar de fora de uma partida, eu quero estar sempre podendo jogar, então eu acho que isso me ajuda bastante a poder estar sempre no nível bom, [...] nunca fico acomodado com a situação. (P1, 27 anos).

Você nunca [pode] se acomodar. O atleta, para atingir o ápice, ele nunca pode achar que aquilo que ele fez ontem foi o suficiente, ele tem que ter uma regularidade, ele não pode ser dez e não pode ser quatro, se ele for cinco e toda vez cinco, não deixar abaixar disso, ele vai conseguir. $O$ atleta precisa ter regularidade e ele consegue isso sendo focado [...]. (P2, 38 anos).

[...] sempre eu quero melhorar [...], quero melhorar nos treinamentos e eu acho que muitos jogadores ficam no meio do caminho por estarem satisfeitos pelo que já conseguiram. (P3, 25 anos).

O relato do $\mathrm{P} 6$, a seguir, deixa evidente a importância da resistência mental para a manutenção de altos níveis de desempenho esportivo:

[...] quando você alcança o topo, você tem que ter uma estabilidade mental, precisa ter resistência mental, porque você é melhor marcado, você é mais pressionado. Acontece tanto na carreira profissional como na seleção. Muitos jogam três jogos e depois não vão mais. Então excelência também é você permanecer muito tempo na seleção. Porque dentro da seleção há mudança de ano em ano e para você permanecer você precisa ter um poder físico e mental muito grande [...] você precisa se cuidar ainda mais, tem que abrir mão ainda mais das coisas e o lado psicológico para você conseguir se manter em alto nível vivendo todas as situações. (P6, 33 anos).

A resistência mental realmente tem sido relacionada por diversos autores como importante característica para a aquisição e manutenção da excelência esportiva (JONES; HANTON; CONNAUGHTON, 2002; FLETCHER; SARKAR, 2012; MORGAN et al., 2013; LIEW et al., 2019; VIDUAL et al., 2019). A resistência mental proporciona ao atleta uma vantagem psicológica sobre os adversários. Nessa perspectiva, Thelwell et al. (2010) identificaram como principais atributos de resiliência psicológica em jogadores de futebol a capacidade de acreditar que alcançará o sucesso, reagir positivamente às situações adversas, controlar as emoções e ter capacidade de ignorar distrações e permanecer focado. Tais características foram apontadas pelos participantes do presente estudo.

O Participante P2 menciona também como um importante complemento para a aquisição e manutenção do desempenho em níveis elevados o acompanhamento psicológico especializado (psicólogo do esporte): [...] "agora imagina um atleta que seja focado, determinado e que tenha o privilégio, porque é um privilégio e que todos os clubes deveriam ter e não têm, de ser acompanhado por um psicólogo do esporte" (P2). Tal afirmação ressalta a importância da Psicologia do Esporte no processo de desenvolvimento esportivo de atletas de alto desempenho (GEE, 2010; RUEDA; LACERDA, 2017). 


\subsection{PREPARAÇÃO PSICOLÓGICA PARA A COMPETIÇÃO}

O desempenho em uma competição é o momento de maior destaque de um atleta. É nesse momento que suas habilidades (física, tática, psicológica) são mais exigidas para alcançar o desempenho almejado. Ouvir música, mentalização e estudar o adversário constituem exemplos do preparo psicológico mencionado pelos participantes, corroborando os achados da literatura (THELWELL et al., 2010; GRUSHKO et al., 2016; WEINBERG; GOULD, 2017).

[...] eu sofro de uma ansiedade que só eu sei. [...] então eu não vejo programa esportivo antes dos jogos, procuro escutar música, me desligar do mundo (P2, 38 anos).

Procuro ouvir música, visualizar o jogo, lembrar de jogos meus importantes. Mentalmente eu visualizo os jogos. Procuro lembrar de quando eu era criança e jogava no interior e penso que hoje estou aqui e mentalizo que vou entrar do mesmo jeito quando jogava lá, que não posso ser diferente. Mas eu procuro sempre estar visualizando os jogos que eu fiz no passado para poder fazer no jogo. (P4, 35 anos).

Eu procuro ficar tranquilo, esvaziar a cabeça [...]. O analista de desempenhomanda o relatório pra gente e eu sempre fico lendo e mentalizando o que eu vou fazer na hora do jogo. Eu fico olhando eu cabeceando a bola, consigo criar as situações de jogo na minha mente assim, sabe? De vez em quando vem alguns pensamentos ruins, mas eu já na hora falo não posso pensar isso, se eu fizer isso eu vou errar e eu falo: 'Não! Esse pensamento não vale e eu consigo mentalizar'. Não sei se tudo o que eu mentalizo acontece na hora do jogo, mas eu tenho procurado fazer isso sempre. (P5, 23 anos).

O participante P6 utiliza como principal estratégia para se preparar psicologicamente estudar os adversários.

Eu estudo muito o adversário, uma leitura. [...]. Eu fui jogar a Copa do Mundo eu fiquei estudando seis meses o time, as seleções, então eu sabia como que um cara, por exemplo, a seleção da Itália era uma qualidade, da Coreia era outra, da Holanda outra, mudava de uma seleção para outra, uma era mais rápida, o outro dribla mais, o outro chuta muito, o outro tem um passe bom, principalmente em grandes jogos. (P6, 33 anos).

O jogo de futebol exige do atleta a tomada de decisão rápida. O atleta ao longo de toda partida precisa observar, processar, avaliar e executar de forma rápida as soluções táticas e técnicas para determinada situação de jogo (COSTA et al., 2010). Esse tipo de preparação cresceu entre os atletas de alto desempenho com o surgimento dos analistas de desempenho. Estes fornecem informações sobre o individual ou coletivo dos seus jogadores e equipes a partir da utilização de vários auxiliares de memória que vão desde o simples lápis e papel até a tecnologia mais sofisticada (SILVA; CASTELO; SANTOS, 2011).

\subsection{CONCENTRAÇÃO: PRIVAÇÃO/PUNIÇÃO}

Fazer parte do elenco de um clube da primeira divisão envolve tornar-se uma pessoa pública, o que pode ter efeito importante na vida privada e social do atleta. Nesse processo, o regime de concentração merece destaque. A forma como é estabelecida pode variar de clube para clube. 
O futebol de campo é uma modalidade que tem um calendário intenso de competições e, ao longo da temporada, competições acontecem de forma simultânea. Um elenco pode estar disputando, por exemplo, a Copa do Brasil, o Campeonato Brasileiro e a Libertadores ao mesmo tempo (GOMES; SOUZA, 2008). Desta forma, os jogadores passam grande parte dos dias em hotéis, viagens e no Centro de Treinamento.

Concentrações no Centro de Treinamento (quando o jogo é em casa) normalmente acontecem com um dia de antecedência. Nessas ocasiões é comum os atletas ficarem hospedados em um hotel no mesmo lugar onde treinam, e cada atleta tem o seu quarto. Quando o jogo é fora, a concentração é mais longa e os jogadores ficam em hotéis da cidade onde será realizado o jogo. Nessas ocasiões, podem dividir o quarto com um colega do elenco.

Quando os atletas estão em regime de concentração usualmente ficam isolados, procuram fazer as refeições em horários preestabelecido e ficam separados dos outros hóspedes. O número de dias em que ficam em regime de concentração pode variar de acordo com o treinador. $\mathrm{Na}$ pré-temporada, alguns treinadores brasileiros optam por manter os atletas concentrados por 15 dias ou mais sem retornar para casa. Portanto, desde o momento em que ingressa na equipe principal de um clube de primeira divisão até o encerramento de sua carreira no futebol, o atleta terá que conviver com as situações de concentração. Como mencionado, as regras estabelecidas podem variar segundo as características do treinador e do clube.

A percepção dos participantes sobre o regime de concentração foi diversa. Dois jogadores avaliaram como positivo (P1 e P3); dois, como desagradável, mas como parte do processo (P4 e P6) e dois como fonte de estresse (P2 e P5). Os relatos a seguir ilustram as diferentes percepções:

[...] Hoje a consciência para a concentração está melhor, mas eu acho chato. Às vezes concentra às 10 horas da manhã da quarta para jogar na quinta às 10 da noite. Assisto TV, leio a bíblia, converso com os amigos, escuto música, vejo filme, um pouco de tudo. A dificuldade é ficar sozinho, ficar no quarto [...]. Eu sempre pedi para a minha família não me passar problema quando estou concentrado (P6, 33 anos).

É um momento de descanso, um momento de refletir, de focar apenas no jogo, de poder sei lá, pensar, fugir um pouco dos problemas extracampo porque se trata de um jogo e você não pode ficar pensando nos problemas que você tem em casa. [...]. Eu me ocupo assistindo filme, escutando música, baixando música, tento, sei lá, ficar deitado, descansar o máximo possível e às vezes jogando videogame. Eu até curto às vezes ficar na concentração, é lógico que não por muito tempo, nem muitos dias, mas eu sou supertranquilo (P1, 27 anos).

Sinceramente, eu não vejo tanta necessidade de concentração. [...]. Você dorme, você acorda, fica deitado o dia inteiro, você não sabe o que pensar e acaba que você pensa coisa boa e coisa ruim, nossa, você fica num tédio. Eu fico muito deitado, o dia todo e assistindo filme, seriado, não fico nem falando muito com as pessoas (P5, 23 anos).

O regime de concentração, as renúncias da vida pessoal e os treinamentos excessivos foram apontados no estudo de Rodrigues (2004) como principais estressores na carreira de jogadores de futebol de elite. 


\section{CONSIDERAÇÕES FINAIS}

Os resultados do presente estudo permitem concluir que o futebol aparece como tema central na vida dos participantes. A família de origem se apresenta como importante referência durante toda a trajetória esportiva; inicialmente no incentivo à realização do sonho de ser jogador de futebol e, posteriormente, no apoio emocional nas adversidades.

Nota-se grande satisfação com a carreira profissional. As convocações da seleção brasileira e a ascensão social merecem destaque nesse processo. É possível observar, também, que os atletas alcançaram a equipe profissional antes de atingirem a idade limite para disputar campeonatos pelas categorias de base e se destacaram precocemente nas diferentes categorias. A maioria dos jogadores entrevistados identificou os problemas extracampo como os mais complexos.

Verifica-se, no relato dos participantes, indicadores de resistência mental e clareza na definição das metas para a carreira esportiva profissional. Merecem destaques o empenho, a disciplina e a busca constante do aperfeiçoamento esportivo dos participantes. A atuação em clube de futebol da primeira divisão e a convocação para a seleção brasileira de futebol materializaram a realização do sonho.

A escolha metodológica do emprego da entrevista em profundidade permitiu ampliar o entendimento do desenvolvimento e a manutenção da excelência esportiva no futebol de campo. Pesquisas dessa natureza devem ser incentivadas para o avanço da ciência do esporte.

\section{REFERÊNCIAS}

ALMEIDA NETO, Honor; SANTOS, Everton Rodrigo. Futebol e infância: formação de crianças e adolescentes das categorias de base do Sport Club Internacional. Revista Prâksis, v. 2, n.12, p. 16-33, 2015.

ANDRADE, Polyanna Peres. "É Muito Mais que Entrar em Campo e Defender um Time": Qualidade de Vida no Trabalho, Bem-Estar/Mal-Estar no Trabalho e Carreira de Jogadores de Futebol Profissional. 77 f. Tese (Doutorado em Psicologia Social) - Programa de PósGraduação em Psicologia Social, do Trabalho e das Organizações - Universidade de Brasília, Brasília, 2016.

ANJOS, José Luiz dos; SANETO, Juliana Guimarães; OLIVEIRA, Andréia Anchieta. Futebol, imagens e profissionalização: a bola rola nos sonhos dos adolescentes. Movimento (Porto Alegre), v. 8, n. 1, p.125-147, 2012. DOI: https://doi.org/10.22456/1982-8918.19415

BALZANO, Otávio Nogueira; RODRIGUES, Abraham Lincoln de Paula; SILVA, Gilberto Ferreira da; MUNSBERG, João Alberto Steffen. O futebol como ferramenta de inclusão social e escolar. Pensar a Prática, v.22, n.54835, p. 1-11, 2019. DOI: https://doi. org/10.5216/rpp.v22.54835 
BELL, Alexandra F; KNIGHT, Camilla J; LOVETT, Victoria E; SHEARER, Catherine. Understanding elite youth athletes' knowledge and perceptions of sport psychology. Journal of Applied Sport Psychology, p.1-40, 2020. DOI: https://doi.org/10.1080/10413200.2020.17 19556

BOSSLE, Fabiano; LIMA, Lucas Oliveira de. Entre a formação na escola e a formação como atleta de futebol profissional: prioridades e influências. Cadernos de Educação Física e Esporte, v.11, n.1, p. 35-43, 2013.

BRANDÃO, Maria Regina Ferreira; MORGADO, Francisco; Machado, Afonso Antonio; ALMEIDA, Pedro. O futebol e seu significado. Motriz, v.14, n.3, p. 233-240, 2008.

CAPRARO, André Mendes; SCHELIGA, Grasielli; CAVICCHIOLI, Fernando; MEZZADRI, Fernando. A imagem do atleta: publicidade em ano de Copa do Mundo de Futebol (Alemanha - 2006). Revista Brasileira de Educação Física e Esporte, v.25, n.1, p. 163171, 2011.

CARVALHO, Jéssica Maria Ferreira; SELVATI; Tamires Silva Golvêa; CAMPOS, Rafaella Cristina; SILVA, Leandro Veloso; SILVA, Giuliano Roberto da. Escolha ou imposição? Estudo de caso sobre o abandono da carreira de atleta. Revista Didática Sistêmica, v.19, n.2, p. 29-40, 2017.

CASANOVA, Filipe; OLIVEIRA, José; MARK, Williams; GARGANTA, Júlio. Expertise and perceptual-cognitive performance in soccer: a review. Revista Portuguesa de Ciências do Desporto, v.9, n.1, p.115-122, 2009.

COSTA, Israel Teoldo; GARGANTA, Júlio; GRECO, Pablo; MESQUITA, Isabel. Análise e avaliação do comportamento tático no futebol. Revista da Educação Física/UEM Maringá, v.21, n.3, p. 443-455, 2010.

CÔTÉ, Jean. The influence of the family in the development of talent in sport. The Sport Psychology, v.13, p. 395-417, 1999.

COULTER, Tristan J.; MALLETT, Clifford J.; GUCCIARDI, Daniel F. Understanding mental toughness in Australian soccer: perceptions of player, parents, and coaches. Journal of Sports Sciences, v.28, n.7, p. 699-716, 2010.

COUTINHO, Patrícia; MESQUITA, Isabel; FONSECA, Antônio M. Talent development in sport: a critical review of pathways to expert performance. International Journal of Sports Science \& Coaching, v.11, n.2, p. 279-293, 2016.

CRUST, Lee; AZADI, Kayvon Mental toughness and athletes'use of psychological strategies. European Journal of Sport Science, v.10, n.1, p. 43-51, 2010.

DAVIDS, K.; ARAÚJO, D. Innate talent in sport: beware of an organism asymmetry-comment on Baker \& Wattie. Current Issues in Sport Science, v.4, n.102, p. 2-4, 2019.

FERREIRA, Márcia Cristina Custódia; MORAES, Luiz Carlos Couto de Albuquerque. Influência da família na primeira fase de desenvolvimento da carreira de nadadores medalhistas olímpicos brasileiros. Motricidade, v. 8, n.2, p.42-51, 2012.

FIGUEIREDO, António J.; GONÇALVES, Carlos E.; SILVA, Manuel J. Coelho; MALINA, Robert M. Characteristics of youth soccer players who drop out, persist or move up. Journal of Sports Sciences, v. 27, n.9, p. 883-891, 2009.

FLETCHER, David; SARKAR, Mustafa. A grounded theory of psychological resilience in Olympic champions. Psychology of Sport and Exercise, v.13, n. 5, p. 669-678, 2012. 
GALLI, Nick; GONZALEZ, Stephen. Psychological resilience in sport: A review of the literature and implications for research and practice. International Journal of Sport and Exercise Psychology. p. 243-257, 2014.

GEE, Chris J. How does sport psychology actually improve athletic performance? A framework to facilitate athletes' and coaches' understanding. Behavior Modification, v.34, n.5, p. 386-402, 2010.

GOMES, Antônio Carlos; SOUZA, Juvenilson de. Futebol: treinamento desportivo de alto rendimento. Porto Alegre: ARTMED, 2008.

GONZÁLEZ, Fernando Jaime; BORGES, Robson Machado; SFALCIN, Alexandre. O sonho acabou! Abandono da carreira esportiva de atletas profissionais de futebol. Corpoconsciência, v.19, n.01, p.11-21, 2015.

GRUSHKO, Alyona; HAIDAMASHKO, Igor; IBRAGIMOV, Renat; KORNIENKO, Dmitry; KOROBEYNIKOVA, Ekaterina; LEONOV, Sergey; VERAKSA, Aleksander. Does the motivation, anxiety and imagery skills contributes to football (soccer) experience? Social and Behavioral Sciences, v.233, p. 181-185, 2016.

JONES, Graham; HANTON, Sheldon; CONNAUGHTON, Declan. What is this thing called mental toughness? An investigation of elite sport performers. Journal of Applied Sport Psychology, v.14, p. 205-218, 2002.

KANNEKENS, Rianne; ELFERINK-GEMSER, M.T.; VISSCHER, C. Positioning and deciding: key factors for talent development in soccer. Scandinavian Journal Medicine Science Sports, v.21, p. 846-852, 2011.

KASUYA, Taizo; NKAZAWA, Tadashi. Psycho-physiology of elite athletes. Bulletin of Sports Research Center, n.37, p. 25-30, 2019.

LIEW, Guo Chen; KUAN, Garry; CHIN, Ngien Siong; HASHIM, Hairul Anuar. Mental Toughness in Sport. German Journal of Exercise and Sport Research, v.49, n.4, p. 381394, 2019.

MARQUES, Maurício Pimenta; SAMULSKI, Dietmar Martin. Análise da carreira esportiva de jovens atletas de futebol na transição da fase amadora para a fase profissional: escolaridade, iniciação, contexto sócio-familiar e planejamento da carreira. Revista Brasileira de Educação Física e Esporte, v.23, n.2, p.103-119, 2009.

MATIAS, Wagner Barbosa. A economia política do futebol e o "lugar" do brasil no mercado-mundo da bola. 510 f. Tese (Doutorado em Educação Física) - Programa de Pós-Graduação em Educação Física da Faculdade de Educação Física. Universidade de Brasília, 2018.

MINAYO, Maria Cecília de Souza. O Desafio do conhecimento: pesquisa qualitativa em saúde, 14. ed. São Paulo: Hucitec, 2014.

MORGAN, Paul B.C.; FLETCHER, David; SARKAR, Mustafa. Defining and characterizing team resilience in elite sport. Psychology of Sport and Exercise, v.14, p. 549-559, 2013.

PEREIRA, Adriana Bernardes. A construção social do tipo "jogador de futebol profissional": um estudo sobre os repertórios usados por jogadores de distintas categorias etárias e por integrantes de suas matrizes. 196p. Tese (Doutorado) - Programa de Psicologia Social da Pontifícia Universidade Católica de São Paulo, 2008. 
PETIOT, Gregory Hallé; AQUINO, Rodrigo; CARDOSO, Felippe; SANTOS, Rodrigo; TEOLDO; Israel. What mental process favours quality decision-making in Young soccer players? Motriz, v.23, n.3, p. 1-7, 2017. DOI: https://doi.org/10.1590/S1980$\underline{6574201700030003}$

PIMENTA, Carlos Alberto Máximo. O sonho na sociedade contemporânea: juventude e futebol. Ponto-e-Vírgula, v.3, p. 112-129, 2008.

RAMADAS, Silvio; SERPA, Sidónio; ROSADO, António. Relação entre características psicológicas e nível de desempenho em jovens jogadores de futebol. Revista Portuguesa de Ciências do Desporto, v.12, n.2, p. 28-44, 2012.

REIS, Cleiton Pereira; FERREIRA, Márcia Cristina Custódia; MORAES, Luiz Carlos Couto de Albuquerque. Apoio dos pais ao desenvolvimento da carreira de atletas masculinos de basquetebol. Revista Brasileira de Ciências do Esporte, v. 38, n.2, p.149-155, 2016.

RIAL, Carmen. Jogadores brasileiros na Espanha: emigrantes porém. Revista de Dialectología y Tradiciones Populares, v. LXI, n. 2, p. 163-190, 2006.

ROCA, André. Perceptual-cognitive expertise and its acquisition in soccer. 167p.Thesis (doctorate degree) - Portuguese Foundation for Science and Technology - Liverpool John Moores University, 2011.

ROCA, André; FORD, Paul R.; WILLIAMS, Andrew Mark. The processes underlying game intelligence skills in soccer players. In. NUNOME, Hiroyuki.; DRUST, Barry.; DAWSON, Brian (ed.) Science and Football VII. New York: Taylor \& Francis, 2013. p. 255-260.

RODRIGUES, Francisco Xavier Freire. Modernidade, disciplina e futebol: uma análise sociológica da produção social do jogador de futebol no Brasil. Sociologias, ano 6, n.11, p. 260-299, 2004.

ROTTA, Tatiana Marcela. Histórias de Vida e o Trabalho de Jogadores de Futebol e suas Implicações com a Produção Social de Subjetividade e Saúde. 540p. Tese de Doutorado - Programa de Pós-Graduação em Saúde Coletiva da Universidade Federal de Santa Catarina, 2014.

RUEDA, Thais Silva; LACERDA, Adiana. Equipe esportiva multi, inter e transdisciplinar: como trabalha o psicólogo. In: MEDEIROS, Clarice; LACERDA, Adriana (org.). Psicologia do esporte na atualidade: reflexões necessárias. São Paulo: Pasavento, 2017. p. 29-46.

SANTOS, Ana Raquel Mendes; CARVALHO, Talita Grazielle Pires; SILVA, Priscilla Pinto Costa; SILVA, Maritza Lordsleem; FREITAS, Clara Maria Silvestre Monteiro. Símbolos e rituais do futebol espetáculo: uma análise das emoções no campo de jogo. Motrivivência, v. 29, n. esp., p. 162-180, 2017. DOI: https://doi.org/10.5007/2175-8042.2017v29nespp162

SARMENTO, Hugo; ANGUERA. M Teresa; PEREIRA, Antonino; ARAÚJO; Duarte. Talent Identification and Development in Male Football: A Systematic Review. Sports Medicine, v.48, p. 907-931, 2018.

SCHARFEN, Hans-Erik; MEMMERT, Daniel. Measurement of cognitive functions in experts and elite athletes: a meta-analytic review. Applied Cognitive Psychology. v.33, n.5, p. 843860, 2019.

SILVA, Pedro Miguel.; CASTELO, Jorge; SANTOS, Pedro. Caracterização do processo de análise do jogo em clubes da $1^{\text {a }}$. liga portuguesa profissional de futebol na época 2005/2006. Revista Brasileira de Educação Física e Esporte, v.25, n.3, p. 441-453, 2011. 
SWANN, Christian; MORAN, Aidan; PIGGOTT, David. Defining elite athletes: issues in the study of expert performance in sport psychology. Psychology of Sport and Exercise, v.16, p. 3-14, 2015.

THELWELL, Richard C; GREENLEES, lain A; WESTON, Neil J V. Examining the use of psychological skills throughout soccer performance. Journal of Sport Behavior, v. 33, n.1, p. 109-127, 2010.

VIDUAL; Marina Belizario de Paiva; GOMES; Sarah Teixeira; FERNANDES, Paula Teixeira. Resiliência, autoestima e autoeficácia no esporte. In: FERNANDES, Paula T (org.), Interdisciplinaridade na Psicologia do Esporte. Curitiba: CRV, 2019. p.105-115.

VIDUAL; Marina Belizario de Paiva; RODRIGUES, Fábio Seiji Uchida; GOMES, Guilherme, GUERRERO, Kaio Borges; FERNANDES, Paula Teixeira. Relação treinador-atleta. In: FERNANDES, Paula T (org.), Interdisciplinaridade na Psicologia do Esporte. Curitiba: CRV, 2019. p.93-104.

WEINBERG, Robert; GOULD, Daniel. Fundamentos da Psicologia do Esporte e do Exercício. 6. ed. Porto Alegre: ARTMED, 2017.

WISNIK, José Miguel. Veneno Remédio: O Futebol e o Brasil. São Paulo: Companhia das Letras, 2008. 
Abstract: This study looked into the construction of the professional trajectories of players from Brazil's national soccer team. Interviews were conducted with six male players who were part of the first team of clubs that play in the first division of the Brazilian Championship. Inclusion criteria: minimum of two years as a professional player and at least one call to the Brazilian national team. Athletes were interviewed individually. According to the analysis of the interviews, soccer is as a central theme in their lives, and their families play important roles in the sports context. The importance of psychological skills for those who reach the elite of professional soccer, and the Brazilian team is confirmed. Understanding the trajectories of elite athletes in sports is important for the advancement of sports science.

Keywords: Professional Competence. Soccer. Athletes. Psychology, Sports.

Resumen: El objetivo de este estudio es comprender la construcción de la trayectoria de futbolistas profesionales de la selección brasileña. Entrevistamos a seis futbolistas, de género masculino, que formaban parte del equipo principal de clubes que compiten en la primera división del Campeonato Brasileño. Criterios de inclusión: mínimo de dos años como jugador profesional y al menos una convocatoria para la Selección Brasileña de Fútbol. Los atletas fueron entrevistados individualmente. A partir del análisis de las entrevistas, se constató que el fútbol es un tema central en sus vidas y que la familia juega un papel importante en el contexto del deporte. La importancia de las habilidades psicológicas se confirma para aquellos que alcanzaron la élite del fútbol profesional y la selección brasileña. Comprender la trayectoria deportiva de los deportistas de élite es un tema de gran relevancia para el avance de la ciencia del deporte.

Palabras clave: Competencia Profesional. Fútbol. Atletas. Psicología del Deporte. 


\section{LICENÇA DE USO}

Este é um artigo publicado em acesso aberto (Open Access) sob a licença Creative Commons Atribuição 4.0 Internacional (CC BY 4.0), que permite uso, distribuição e reprodução em qualquer meio, desde que o trabalho original seja corretamente citado. Mais informações em: https://creativecommons.org/licenses/by/4.0

\section{CONFLITO DE INTERESSES}

Os autores declararam que não existe nenhum conflito de interesses neste trabalho.

\section{CONTRIBUIÇÕES AUTORAIS}

Juliane Jellmayer Fechio: Planejamento do estudo, coleta de dados, análise de dados e escrita do artigo.

Maria Stella Peccin: Planejamento do estudo, orientação da coleta de dados, análise de dados e escrita do artigo.

Ricardo da Costa Padovani: Planejamento do estudo, orientação da coleta de dados, análise de dados e escrita do artigo.

\section{FINANCIAMENTO}

O presente trabalho foi realizado sem o apoio de fontes financiadoras.

\section{ÉTICA DE PESQUISA}

O projeto de pesquisa foi encaminhado e aprovado pelo comitê de pesquisa da UNIFESP, protocolo n. 394.420 .

\section{COMO REFERENCIAR}

FECHIO, Juliane Jellmayer; PECCIN, Maria Stella; PADOVANI, Ricardo da Costa. Trajetória esportiva e habilidades psicológicas de jogadores de futebol da seleção brasileira. Movimento (Porto Alegre), v.27, p.e27071, jan./dez. 2021. Disponível em: https://seer.ufrgs.br/Movimento/article/view/113626. Acesso em: [dia] [mês abreviado]. [ano]. DOI: https://doi.org/10.22456/1982-8918.113626

\section{RESPONSABILIDADE EDITORIAL}

Alex Branco Fraga*, Elisandro Schultz Wittizorecki, Ivone Job*, Mauro Myskiw*, Raquel da Silveira*

*Universidade Federal do Rio Grande do Sul, Escola de Educação Física, Fisioterapia e Dança, Porto Alegre, RS, Brasil. 